(RESEARCH ARTICLE)

\title{
Awareness of HIV status and partner disclosure among antenatal clinic attendants: experience from a regional hospital in Ghana
}

\author{
Boniface Mensah ${ }^{1}$, Betty Roberta Norman ${ }^{2}$, John Jude Kweku Annan ${ }^{3,}{ }^{*}$, Anthony Enimil ${ }^{4}$ and Martin Agyei 2 \\ ${ }^{1}$ Kumasi South Hospital P.O. Box 1908, Atonsu Agogo, Kumasi, Ghana. \\ ${ }^{2}$ Department of Internal Medicine School of Medicine and Dentistry, College of Health Sciences Kwame Nkrumah \\ University of Science and Technology, Kumasi, Ghana. \\ ${ }^{3}$ Department of Obstetrics and Gynaecology School of Medicine and Dentistry, College of Health Sciences Kwame \\ Nkrumah University of Science and Technology, Kumasi, Ghana. \\ ${ }^{4}$ Department of Child Health \\ School of Medicine and Dentistry, College of Health Sciences Kwame Nkrumah University of Science and Technology, \\ Kumasi, Ghana.
}

Publication history: Received on 15 November 2020; revised on 25 November 2020; accepted on 29 November 2020

Article DOI: https://doi.org/10.30574/wjarr.2020.8.3.0449

\begin{abstract}
Introduction: A pregnant woman's knowledge of her human immune deficiency virus (HIV) serostatus and that of her sexual partner and the disclosure of her serostatus to the partner puts her in a better position to make informed choices about her pregnancy, adopt strategies to prevent mother to child transmission (PMTCT) of HIV and reduce sexual transmission of HIV. Some pregnant women however opt out of antenatal HIV testing while others have challenges with partner disclosure. This study sought to assess the pregnant women's knowledge of their HIV serostatus and that of their partners, and disclosure to partners about their serostatus.
\end{abstract}

Methods: An ethically approved cross-sectional descriptive study was conducted at the antenatal clinic (ANC) of the Kumasi South Hospital, Ghana from the period $8^{\text {th }}$ March to $5^{\text {th }}$ April, 2016. A structured questionnaire was administered to 407 ANC attendants who were randomly selected to participate in the study. Data entry was in Microsoft Excel and analyzed using R Core Team (2014).

Results: The study showed that $80.1 \%(n=326 / 407)$ of the participants knew their HIV serostatus. Of these, 18.1\% (n $=59 / 326)$ knew prior to the current pregnancy and $81.9 \%(n=267 / 326)$ were told during the current pregnancy. Among those who knew their HIV serostatus, the majority [83.1\%; ( $n=271 / 326)]$ had disclosed to their partners. Most of the participants [70.76\%; $(n=288 / 407)]$ had no knowledge of their partners' status.

Conclusion: Every pregnant woman should know their HIV status, disclose it to their sexual partners and know the status of their sexual partners as this will PMTCT, reduce HIV transmission and acquisition among sero- discordant couples.

Keywords: Human immune deficiency virus (HIV); Prevention of mother to child transmission (PMTCT); Antenatal HIV testing; Acquired immune deficiency syndrome; HIV status disclosure

\section{Introduction}

Since the first reported case of acquired immune deficiency syndrome (AIDS) in 1981, the number of people living with human immune deficiency virus (PLWHIV) continues to increase and human immune deficiency virus (HIV) related

\footnotetext{
${ }^{*}$ Corresponding author: John Jude Kweku Annan

Department of Obstetrics and Gynaecology School of Medicine and Dentistry, College of Health Sciences Kwame Nkrumah University of Science and Technology, Kumasi, Ghana. 
illnesses are still one of the leading causes of death worldwide [1]. The burden is highest in sub-Saharan Africa where $63 \%$ of PLWHIV reside [2].

Central to the control of HIV is the diagnosis and treatment of the infected individuals and prevention of new infections. Voluntary HIV testing and counselling serve these goals. HIV-infected women who know their sero-status are in a better position to make informed choices about their reproductive life, and if pregnant, to access specific interventions, such as antiretroviral treatment, decide on mode of delivery and infant feeding counselling and support, which can significantly reduce the risk of mother-to-child transmission of HIV. Reports indicated that up to one-third of individuals diagnosed with HIV infection continue to have unprotected sex without informing their sexual partners who may be of positive, negative or of unknown sero-status [3]. Partner disclosure may motivate partner testing, encourage changes in sexual and social behaviour and ultimately decrease HIV transmission. It also affords the individual the opportunity for social support, improved access to care including antiretroviral treatment and prevention of mother-to-child transmission (PMTCT) interventions, increased opportunities to discuss and implement HIV risk reduction strategies with partners and to plan for the future. Thus, disclosure of HIV status is an important prevention strategy. National population surveys and epidemiologic studies indicate that the majority of African HIV infected individuals are married or in a stable long-term relationship [4]. Where the HIV status of both partners is known, measures can be taken to prevent infection in the seronegative partner and treat the affected one.

Recently, increased attention to transmission within sero-discordant couples has highlighted the potential role of disclosure as a way to encourage prevention [5]. Advantages of disclosure of HIV status by pregnant women include increased emotional and financial support, freedom to use their HIV drugs in front of sexual partners, and freedom to implement the feeding option they choose for their new-born [6]. However, HIV sero-status disclosure may be associated with some negative outcomes: reduced social support [7], blame for testing without partner's consent [8], separation or divorce [9] and partner violence [10].

In Ghana despite the availability of counselling and testing centers, voluntary testing for HIV is not the norm. Majority of HIV testing are health provider initiated for diagnostic purposes. Despite the scaling up of HIV testing for pregnant women, some still opt out of testing and others after testing, do not disclose their status to their partners as they are more afraid of the consequences rather than the benefits of getting care and support and preventing transmission to their unborn babies.

This research sought to determine the knowledge of HIV sero-status among pregnant women, the rate of sero-status disclosure to their partners whether positive or negative and to assess their knowledge of their partners' HIV status. This will help in planning programs that will improve knowledge, facilitate disclosure and ultimately reduce HIV acquisition and transmission in sero-discordant sexual relationships and reduce MTCT.

\section{Methods}

This cross-sectional descriptive study was conducted at the antenatal clinic (ANC) of the Kumasi South Hospital, Ghana from the period $8^{\text {th }}$ March 2016 to $5^{\text {th }}$ April, 2016. The principal objective was to assess the knowledge of antenatal clinic attendants at the Kumasi South Hospital of their HIV status and partner disclosure of the status and its impact.

The Kumasi South Hospital is a government facility located in the Ashanti Region of Ghana. This hospital was chosen for the study because it has a very large HIV clinic and has an effective PMTCT program. It runs a daily antenatal clinic that sees about 150 clients per day. The patients are given HIV education, counselled and offered HIV testing at the booking visit. Clients are encouraged to disclose their HIV status after they have been tested.

The study population was antenatal attendants at the Kumasi South Hospital from $8^{\text {th }}$ March to $5^{\text {th }}$ April, 2016. Antenatal clinic attendants below the age of 18 years were excluded from the study. After sample size calculation, 407 women were recruited into the study.

Recruitment into the study was done at the antenatal clinic by a random sampling technique. A data collection tool (questionnaire) designed for the purpose of the study was pre-tested and used to collect the data. The purpose of the study was fully explained to the participants and an informed consent form was signed if a woman agreed to be enrolled into the study. Participants who could not sign were made to thumbprint. The participants were then interviewed using the questionnaires with both closed and open ended questions that addressed the principal and specific objectives.

Ethical approval for the study was obtained from the hospital ethical committee. Confidentiality was maintained throughout the study. Respondents did not receive any incentives to participate in this study. No participant was forced 
or coerced to answer questions they did not wish to answer. Information extracted include patient demographics, awareness of HIV status, prevention of mother to child transmission, disclosure of HIV status to partner and knowledge of partner's HIV status.

In computing the sociodemographic characteristics of the study participants, frequencies and percentages were used whilst chi square test was used to assess the relationship between disclosure of HIV status and other variables. The results are presented in the form of tables and figures.

\section{Results}

\subsection{Demographic Characteristics}

The demographic characteristics of the study participants are depicted in Table 1.

Table 1 Showing Demographic Characteristics of Study Participants

\begin{tabular}{|c|c|c|}
\hline Variable & Number & Percentage (\%) \\
\hline \multicolumn{3}{|l|}{ Age (years) } \\
\hline 25 and below & 147 & 36.12 \\
\hline $26-30$ & 150 & 36.86 \\
\hline $31-35$ & 62 & 15.23 \\
\hline 36 and above & 48 & 11.79 \\
\hline TOTAL & 407 & 100.00 \\
\hline \multicolumn{3}{|l|}{ Education } \\
\hline None & 31 & 7.62 \\
\hline Basic & 28 & 6.88 \\
\hline Secondary & 86 & 21.13 \\
\hline Tertiary & 262 & 64.37 \\
\hline TOTAL & 407 & 100.00 \\
\hline \multicolumn{3}{|l|}{ Marital status } \\
\hline Single & 59 & 14.50 \\
\hline Married & 232 & 57.00 \\
\hline Divorced & 1 & 0.25 \\
\hline Cohabiting & 115 & 28.25 \\
\hline TOTAL & 407 & 100.00 \\
\hline \multicolumn{3}{|l|}{ Parity } \\
\hline $0-1$ & 235 & 57.74 \\
\hline $2-3$ & 150 & 36.85 \\
\hline $4-5$ & 22 & 5.40 \\
\hline TOTAL & 407 & 100.00 \\
\hline \multicolumn{3}{|l|}{ Religion } \\
\hline Moslem & 25 & 6.14 \\
\hline Christian & 379 & 93.12 \\
\hline Others & 3 & 0.74 \\
\hline TOTAL & 407 & 100.00 \\
\hline \multicolumn{3}{|l|}{ Employment } \\
\hline Unemployed & 78 & 19.12 \\
\hline Traders & 301 & 74.0 \\
\hline Farmer & 1 & 0.25 \\
\hline Professional & 27 & 6.63 \\
\hline TOTAL & 407 & 100.00 \\
\hline
\end{tabular}

The age range was 19 - 46 with the mean age being 27.94 (SD: 5.16). 36.12\% ( $\mathrm{n}=147 / 407$ ) of the study participants were aged 25 years and below. $36.86 \%(n=150 / 407)$ were between $26-30$ years and $11.79 \%$ were above 35 years of 
age. Antenatal clinic attendants below the age of 18 years were excluded from the study. Majority of the women $92.38 \%$ $(\mathrm{n}=376 / 407)$ had some form of formal education with $64.37 \%(\mathrm{n}=262 / 407)$ having tertiary education. More than half $(57 \% ; n=232 / 407)$ were married, $28.25 \%(n=115 / 407)$ were co-habiting and $14.50 \%(n=59 / 407)$ were single. Table 1 also depicts parity of the respondents: $57.74 \%(n=235 / 407)$ of the study participants either carrying their first pregnancy (primigravida) or had one child, 36.85\% ( $\mathrm{n}=150 / 407)$ had 2 or 3 children and 5.40\% (n=22/407) had 4 or 5 children. For religious affiliation, 93.12\% $(n=379 / 407)$ of the participants were Christians, $6.14 \%(n=25 / 407)$ were Moslems and $0.73 \%(n=3 / 407)$ were of other religions. Most respondents (80.88\%; $n=329 / 407)$ were employed (involved in farming, trading and professional work) whilst 19.12\% ( $\mathrm{n}=78 / 407)$ were unemployed.

\subsection{Awareness of HIV Status}

Table 2 depicts awareness of HIV status of study participants. A greater number of participants 80.1\% $(\mathrm{n}=326 / 407)$ knew their HIV status compared to $19.9 \%(n=81 / 407)$ who were unaware. Out of the number of people who knew their HIV status, $18.1 \%(n=59 / 326)$ knew their status prior to the current pregnancy whilst $81.9 \%(n=267 / 326) \mathrm{knew}$ their HIV status during the current pregnancy. A greater proportion of women $(61.7 \% ; n=251 / 407)$ had not received any education on HIV during the current pregnancy whilst 38.3\% ( $\mathrm{n}=156 / 407)$ had. Additionally, more women, $82.1 \%$ $(\mathrm{n}=334 / 407)$ had tested for HIV infection during the current pregnancy while $17.9 \%(\mathrm{n}=73 / 407)$ had not. Out of the number of participants who had not tested for HIV infection during the current pregnancy, 80.8\% $(n=59 / 73)$ were on their first ANC visit, $16.4 \%(\mathrm{n}=12 / 73)$ had no reason for not testing and $2.8 \%(\mathrm{n}=2 / 73)$ had not tested due to nonavailability of test kits.

Table 2 Showing Awareness of HIV status of Study Participants

\begin{tabular}{|c|c|c|}
\hline Variable & Number & Percentage (\%) \\
\hline \multicolumn{3}{|l|}{ Awareness of HIV status } \\
\hline Yes & 326 & 80.1 \\
\hline No & 81 & 19.9 \\
\hline TOTAL & 407 & 100.0 \\
\hline \multicolumn{3}{|l|}{ When was this known } \\
\hline Prior to this pregnancy & 59 & 18.1 \\
\hline During this pregnancy & 267 & 81.9 \\
\hline TOTAL & 326 & 100.0 \\
\hline \multicolumn{3}{|l|}{ Received education on HIV } \\
\hline Yes & 156 & 38.3 \\
\hline No & 251 & 61.7 \\
\hline TOTAL & 407 & 100.0 \\
\hline \multicolumn{3}{|c|}{ Test for HIV during this pregnancy } \\
\hline Yes & 334 & 82.1 \\
\hline No & 73 & 17.9 \\
\hline TOTAL & 407 & 100.0 \\
\hline \multicolumn{3}{|l|}{ Why decline HIV test } \\
\hline First Antenatal Clinic (ANC) & 59 & 80.8 \\
\hline No Reason & 12 & 16.4 \\
\hline No test kits & 2 & 2.8 \\
\hline TOTAL & 73 & 100.0 \\
\hline
\end{tabular}




\subsection{PMTCT}

From Table 2, 334 out of 407 respondents had HIV test. Table 3 shows PMTCT of seropositive patients. It shows that $2.4 \%(n=8 / 334)$ of the participants had tested positive for HIV during this or a previous pregnancy with $97.6 \%(n=$ $326 / 334)$ testing negative. The HIV diagnosis was made in $62.5 \%(\mathrm{n}=5 / 8)$ of participants prior to this pregnancy and in $37.5 \%(n=3 / 8)$ during the current pregnancy. Of the HIV positive participants, $42.9 \%$ ( $n=3 / 7$ ) were on TDF/3TC/EFV, 14.2\% (n=1/7) were on TDF/3TC/NVP and 42.9\% $(\mathrm{n}=3 / 7)$ on ZDV/3TC/NVP. Table 3 also shows that $42.8 \%(\mathrm{n}=3 / 7)$ have been on ART for up to a year, 28.6\% $(\mathrm{n}=2 / 7)$ have been on ART for $1-5$ years and $28.6 \%(\mathrm{n}=$ 2/7) had been on ART for 6-10 years. With respect to previous PMTCT, 50\% $(\mathrm{n}=4 / 8)$ had PMTCT in the previous pregnancy.

Table 3 Showing PMTCT of Seropositive Participants

\begin{tabular}{|c|c|c|}
\hline Variable & Number & Percentage (\%) \\
\hline \multicolumn{3}{|c|}{ Diagnosed Positive during PMTCT } \\
\hline Yes & 8 & 2.4 \\
\hline No & 326 & 97.6 \\
\hline TOTAL & 334 & 100.0 \\
\hline \multicolumn{3}{|c|}{ When was HIV Diagnosis made } \\
\hline Prior this pregnancy & 5 & 62.5 \\
\hline During this pregnancy & 3 & 37.5 \\
\hline TOTAL & 8 & 100.0 \\
\hline \multicolumn{3}{|l|}{ HAART Type } \\
\hline TDF/3TC/EFV & 3 & 42.9 \\
\hline TDF/3TC/NVP & 1 & 14.2 \\
\hline ZDV/3TC/NVP & 3 & 42.9 \\
\hline TOTAL & 7 & 100.0 \\
\hline \multicolumn{3}{|l|}{ Length on HAART } \\
\hline Up to 1 year & 3 & 42.8 \\
\hline $1-5$ years & 2 & 28.6 \\
\hline $6-10$ years & 2 & 28.6 \\
\hline TOTAL & 7 & 100.0 \\
\hline \multicolumn{3}{|c|}{ PMCT in previous pregnancy } \\
\hline Yes & 4 & 50 \\
\hline No & 4 & 50 \\
\hline TOTAL & 8 & 100 \\
\hline
\end{tabular}

\subsection{Disclosure of Status}

Table 4 shows that out of the participants who knew their HIV status, $83.1 \%(n=271 / 326)$ had disclosed their status to their partners with $16.9 \%(n=55 / 326)$ not disclosing their status. $60.00 \%(n=33 / 55)$ of those who had not disclosed did not deem it necessary to disclose as they were HIV negative. $29.08 \%(\mathrm{n}=16 / 55)$ had not disclosed because they had not been asked by their partners, 3.64\% $(n=2 / 55)$ were afraid of being divorced if they disclosed and the same number had not disclosed because their partners were violent. All the participants had disclosed voluntarily. 8.49\% (n $=23 / 271$ ) of the participants who had disclosed reported being happy, $0.37 \%(n=1)$ of them reported the partner accepted the results and $91.14 \%(n=247 / 271)$ reported no positive impact. None of the participants who had disclosed experienced a negative impact of disclosure. 
Table 4 Showing Disclosure of Status to Partners

\begin{tabular}{|l|l|l|}
\hline Variable & Number & Percentage (\%) \\
\hline Disclosure to partner & 271 & 83.1 \\
\hline Yes & 55 & 16.9 \\
\hline No & 326 & 100.0 \\
\hline TOTAL & \multicolumn{2}{|l|}{} \\
\hline If no, why have you not disclosed & 60.00 \\
\hline My status is negative & 33 & 29.08 \\
\hline He hasn't asked & 16 & 3.64 \\
\hline Recently got to know & 2 & 3.64 \\
\hline Will divorce me & 2 & 3.64 \\
\hline Violence & 2 & 100.00 \\
\hline TOTAL & 55 & \\
\hline How was disclosure done & \multicolumn{2}{|l|}{} \\
\hline Voluntary & 271 & 100 \\
\hline TOTAL & 271 & 100 \\
\hline Positive response & 23 & 8.49 \\
\hline Happy & 1 & 0.37 \\
\hline Accepted & 247 & 91.14 \\
\hline None & 271 & 100.00 \\
\hline TOTAL & 271 & 100 \\
\hline Negative response & \multicolumn{2}{|l|}{} \\
\hline None & \multicolumn{2}{|l|}{} \\
\hline
\end{tabular}

\subsection{Knowledge of Partners' and Children's HIV Status}

Table 5 shows that a majority, $97.54 \%$ ( $n=397 / 407)$ of participants had a previous partner who was sick or dead whilst $2.46 \%(\mathrm{n}=10 / 407)$ had no such history. $29.24 \%(\mathrm{n}=119 / 407)$ of the participants were aware of their partners' status but majority, $70.76 \%(\mathrm{n}=288 / 407)$ did not know their partners' status. For the participants who didn't know their partners' status, $81.9 \%(n=236 / 288)$ had not asked their partners' of their status. $18.1 \%(n=52 / 288)$ of the participants had partners who had not tested for HIV infection. Of the participants who knew their partners' status, $1.67 \%(\mathrm{n}=2 / 119)$ had partners who had tested positive and on ART and 98.33\% ( $\mathrm{n}=117 / 119)$ who had tested negative. Condon use was never done in $83.04 \%(\mathrm{n}=338 / 407)$ of respondents but $1.48 \%(\mathrm{n}=6 / 407)$ always use condom whilst $15.48 \%(\mathrm{n}=63 / 407)$ use condom at times during sexual intercourse. Of the 292 participants who had children, 27.05\% ( $\mathrm{n}=79 / 292)$ have had their children screened for HIV infection whilst 72.95\% $(\mathrm{n}=213 / 292)$ had not done so. All the children who were tested, tested negative for HIV infection.

Table 5 Showing Participants Knowledge of Partners' and Children's HIV Status

\begin{tabular}{|l|l|l|}
\hline Variable & Number & Percentage (\%) \\
\hline Past Partner sick or Dead & 10 & 2.46 \\
\hline Yes & 397 & 97.54 \\
\hline No & 407 & 100.00 \\
\hline TOTAL & 119 & 29.24 \\
\hline Know partners' HIV status & 288 & 70.76 \\
\hline Yes & 407 & 100.0 \\
\hline No &
\end{tabular}




\begin{tabular}{|c|c|c|}
\hline \multicolumn{3}{|c|}{ If No, why don't you know? } \\
\hline Not asked & 236 & 81.9 \\
\hline Not tested & 52 & 18.1 \\
\hline TOTAL & 288 & 100.0 \\
\hline \multicolumn{3}{|c|}{ Spouse HIV status } \\
\hline Positive & 2 & 1.67 \\
\hline Negative & 117 & 98.33 \\
\hline TOTAL & 119 & 100.00 \\
\hline \multicolumn{3}{|c|}{ Partner on HAART } \\
\hline Yes & 2 & 100 \\
\hline Total & 2 & 100 \\
\hline \multicolumn{3}{|c|}{ Condom use } \\
\hline Always & 6 & 1.48 \\
\hline At times & 63 & 15.48 \\
\hline Never & 338 & 83.04 \\
\hline TOTAL & 407 & 100.00 \\
\hline \multicolumn{3}{|c|}{ Children screened for HIV } \\
\hline Yes & 79 & 27.05 \\
\hline No & 213 & 72.95 \\
\hline TOTAL & 292 & 100.00 \\
\hline \multicolumn{3}{|c|}{ Any child HIV positive } \\
\hline No & 79 & 100 \\
\hline Yes & 0 & 0 \\
\hline TOTAL & 79 & 100 \\
\hline
\end{tabular}

Figure 1 below shows the age ranges with the disclosure of HIV status. In this study, 83.04\% of the participants who were aged 25 years and below had disclosed their status to their partners. $81.10 \%$ of participants aged between $26-30$ years, $87.27 \%$ of those aged between $31-35$ years and $81.82 \%$ of those aged above 35 years had all disclosed their HIV serostatus to their partners.

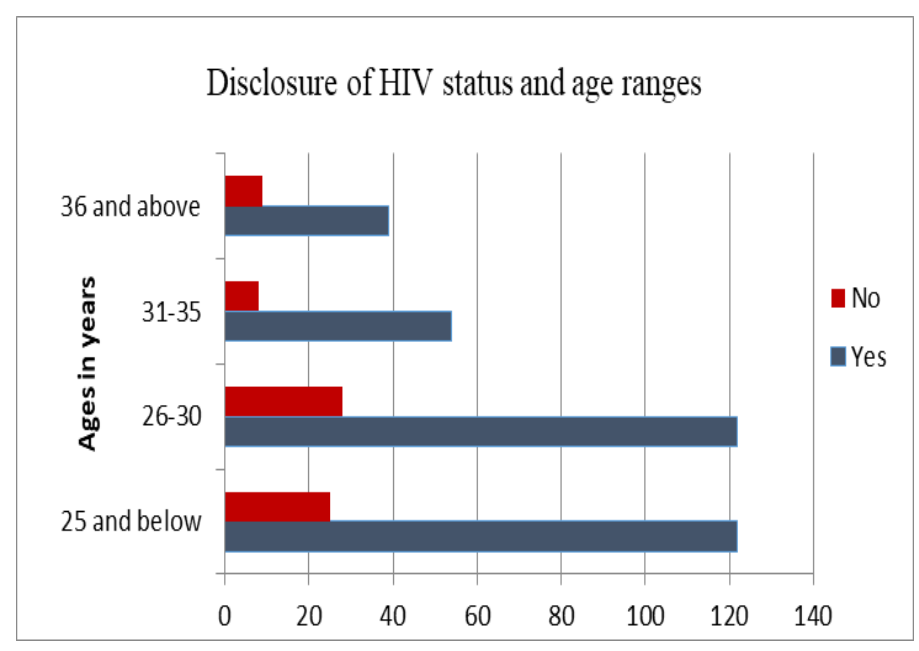

Figure 1 Showing Disclosure of HIV status and age ranges.

Figure 2 below shows $74.6 \%$ of the participants who were unemployed had disclosed their status to the partners with $25.4 \%$ of unemployed participants not disclosing their status. Those who were traders recorded $84.6 \%$ of them disclosing their status with the rest not disclosing. Participants with professional carriers had $86.4 \%$ disclosure rate. 


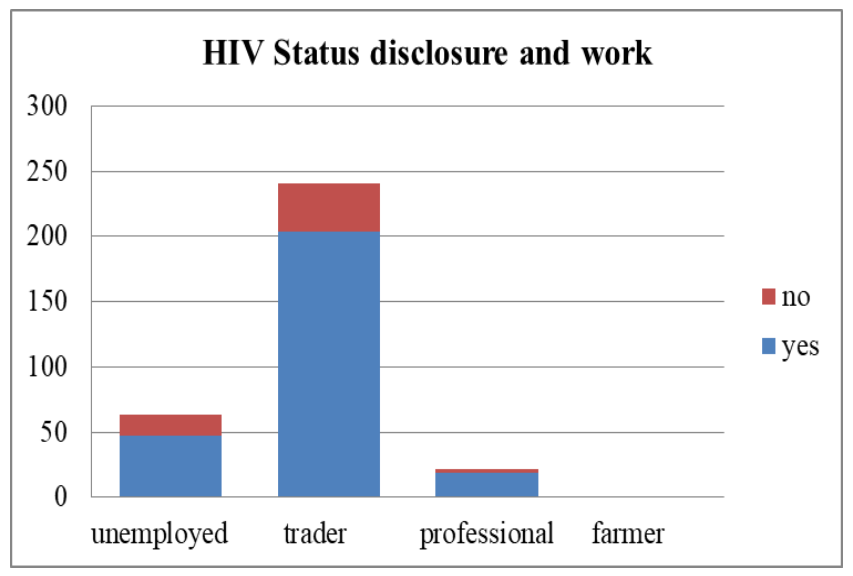

Figure 2 Showing the Occupation of the participants in relation to HIV status disclosure

Figure 3 below shows the disclosure of HIV status and the level of education with $90.1 \%, 85.5 \%, 82 \%$ and $75 \%$ disclosure in participants who have had basic, secondary, tertiary levels and no level education respectively.

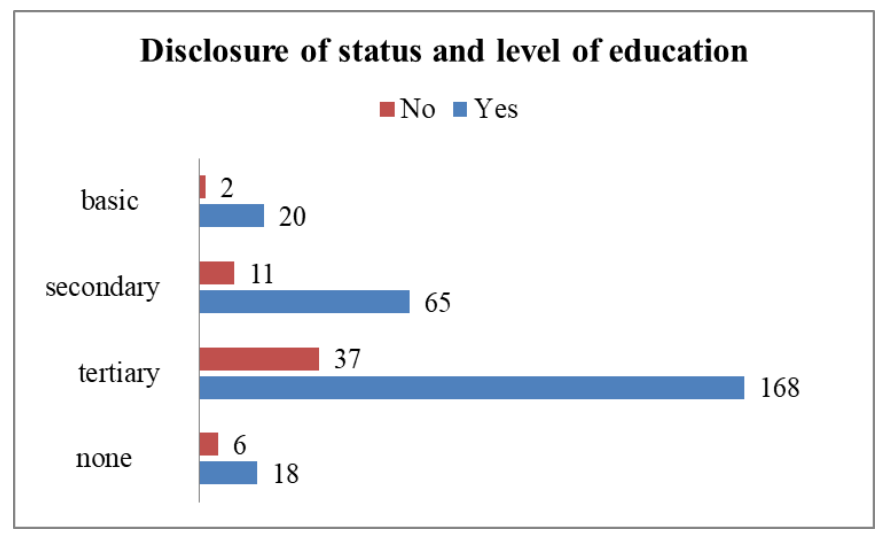

Figure 3 Showing the relationship between the Disclosure of HIV Status and level of education

Figure 4 below shows $84.6 \%$ of the participants who never use condom had disclosed their HIV status. Participants who at times use condom recorded $72.9 \%$ disclosure rate. Participants who always use condom recorded $83.3 \%$ disclosure rate.

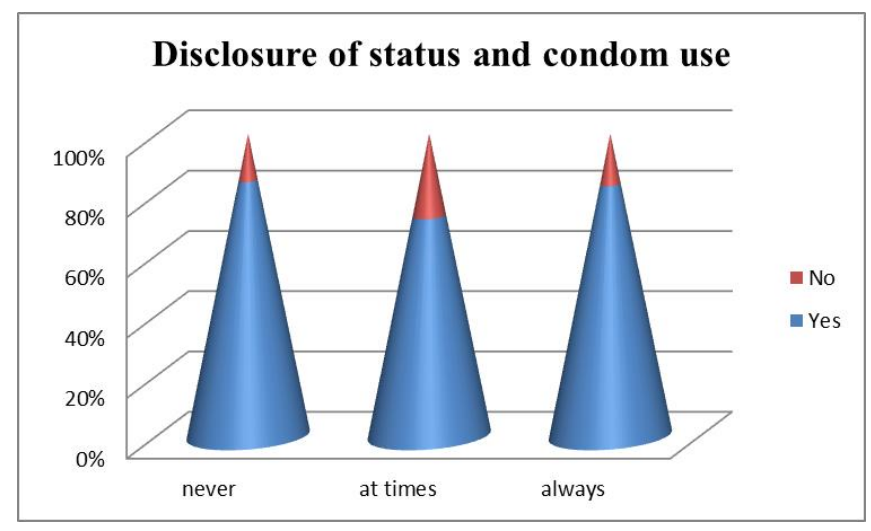

Figure 4 Showing the relationship between Disclosure of HIV status and condom use.

Figure 5 below shows the disclosure status and testing in pregnancy. Of the participants who had tested during pregnancy, $97 \%$ had disclosed their HIV status compared to $94.6 \%$ of the participants who had tested prior to the pregnancy disclosing their HIV status. 


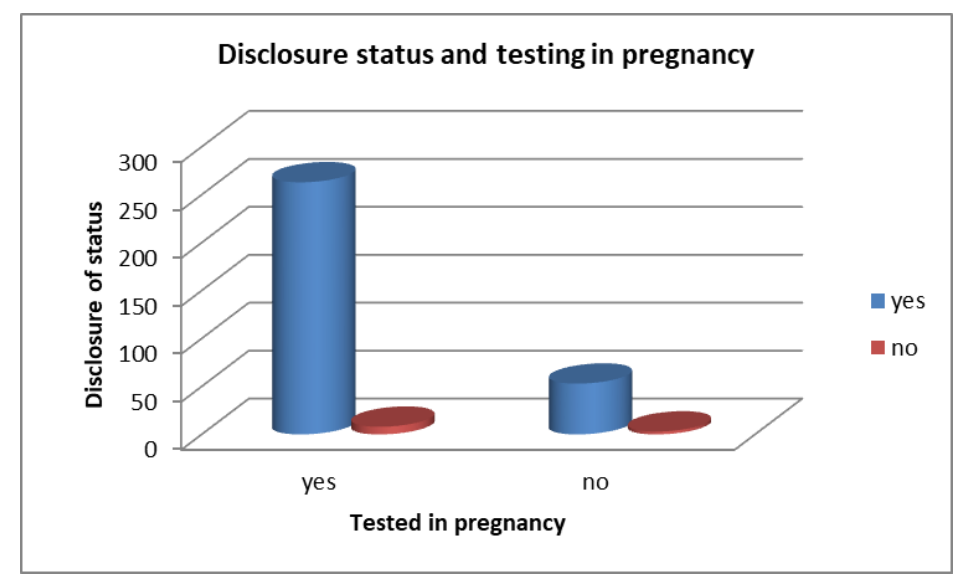

Figure 5 Showing the relationship between Disclosure of HIV status and HIV testing in pregnancy

Table 6 shows the relationship between Disclosure of HIV status and several variables. There is no significance relationship between disclosure of participants' HIV status and knowledge of HIV status (p-value 0.51). However, having had HIV education, participants' testing for HIV in current pregnancy, knowing partner's HIV status and having had children tested for HIV had a statistically significant relationship with disclosure of their HIV status (p-values 0.3, 0.4, 0.00 and 0.21 respectively)

Table 6 Showing Results of a chi square test assessing relationship between Disclosure of HIV status and several variables.

\begin{tabular}{|c|c|c|c|c|}
\hline \multirow[t]{2}{*}{ Variable } & \multicolumn{2}{|c|}{$\begin{array}{l}\text { Disclosure of HIV status of } \\
\text { pregnant women }\end{array}$} & \multirow[t]{2}{*}{ OR (95\% CI) } & \multirow[t]{2}{*}{ p-value } \\
\hline & Yes & No & & \\
\hline \multicolumn{5}{|c|}{ Knowledge of HIV } \\
\hline Prior PMTCT & 50 & 8 & \multirow[b]{2}{*}{$1.31(0.57,3.42)$} & \multirow[b]{2}{*}{0.51} \\
\hline During PMTCT & 219 & 46 & & \\
\hline \multicolumn{5}{|l|}{ HIV Education } \\
\hline Yes & 122 & 21 & \multirow[b]{2}{*}{$1.36(0.73,2.6)$} & \multirow[b]{2}{*}{0.3} \\
\hline No & 149 & 35 & & \\
\hline \multicolumn{5}{|c|}{ Testing in Pregnancy } \\
\hline Yes & 263 & 53 & \multirow[b]{2}{*}{$1.86(0.31,8.06)$} & \multirow[b]{2}{*}{0.4} \\
\hline No & 8 & 3 & & \\
\hline \multicolumn{5}{|c|}{ Know partners HIV status } \\
\hline Yes & 106 & 6 & \multirow[b]{2}{*}{$5.35(2.18,15.76)$} & \multirow[b]{2}{*}{0.00} \\
\hline No & 165 & 50 & & \\
\hline \multicolumn{5}{|c|}{ Children screened for HIV } \\
\hline Yes & 60 & 8 & \multirow[b]{2}{*}{$1.7(0.71,4.52)$} & \multirow[b]{2}{*}{0.21} \\
\hline No & 137 & 31 & & \\
\hline
\end{tabular}

\section{Discussion}

\subsection{Demographics}

The study showed that majority of the participants (72.98\%) were between 20-30 years of age. This represents the peak reproductive age for most women. The age of pregnant women is known to influence disclosure of their HIV serostatus. Some studies found that younger women under the age of 24 years were more likely to disclose their status than older women $[11,12]$. This study, however, showed a high disclosure rate across all age categories: $83.04 \%$ for those aged 25 
years and below, $81.10 \%$ for those aged between $26-30$ years, $87.27 \%$ for those aged between $31-35$ years and $81.82 \%$ of those aged above 35 years.

The study showed that majority of study participants (92\%) had some formal education (basic to tertiary level). The urban settings where this study was conducted could possibly account for this. Being educated may have positive implications for HIV status disclosure as some studies have reported that women with higher level of education were more likely to disclose their HIV test results to their partners than woman who were illiterates [13, 14].

The majority of the participants were married (57\%) or co-habiting (28.25\%). Pregnant women from these stable family environments may have challenges with disclosure due the fear of violence, rejection, accusations of infidelity, abandonment, and loss of economic support from a partner [15]. In resource poor countries where women are not economically independent of their partners, the fear of losing this important source of support is a real cause for worry for these women. On the other hand, supportive husbands or partners may offer the best support for seropositive pregnant women to facilitate a successful PMTCT.

The majority of the participants (57.74\%) either had no child or had one child, with 36.85\% having 2 or 3 children. This may have positive implication to the successful uptake of PMTCT as the mothers will be eager to have healthy children knowing the importance of having children in our society. This study showed that $80.88 \%$ of the participants had some sort of livelihood (trading, professional careers and farming) but whether the income generated was enough to make them financially independent and responsible is difficult to determine. Being financially dependent may mean women would have challenges with disclosure due to fear of loss of economic support.

\subsection{Awareness of HIV status}

There was a high level of awareness of HIV status (80.1\%) among study participants. This could be attributable to the scale up of the PMTCT programs in hospitals across the country. Pregnant women are given an opt-out option of HIV testing and women are told of their HIV serostatus. Among respondents who knew their HIV status, 18.1\% knew it prior to their current pregnancy whilst $81.9 \%$ knew it during the current pregnancy. This compares to a Tanzanian serostatus disclosure study which showed $80.8 \%$ of pregnant women learnt of their HIV status during their current pregnancy [16]. Knowledge of one's preconception HIV status is one of the important preventive strategies for an effective PMTCT program. The HIV infected woman can be started on ART for her own health and for preventing transmission to her unborn child and sexual partner. Additionally, she will be able to make an informed decision before embarking on a pregnancy.

The study showed a high acceptance of the HIV testing offered at the ANC as the majority of the participants (82.1\%) had tested for HIV infection during the current pregnancy. This number could have been higher as at the time of the study, there was a problem of non-availability of test kits at the clinic.

This study showed that $2.4 \%$ of the participants had tested positive for HIV during this or a previous pregnancy. In the 2014 HIV status report by Ghana AIDS Commission (GAC), out of 601,726 pregnant women who tested for HIV, 12,583 representing 2.1\% were found to be HIV positive. $87.5 \%$ of the HIV positive participants were on ART. This falls short of the National AIDS Commission Programme recommendation that all HIV positive pregnant women be treated with ART. Even though knowledge of HIV status and acceptability was high, the level of HIV education received from the ANC by the participants was low (38.3\%). This could be due the fact that some of the participants may arrive at the clinic after the health talk is given usually before consultation starts at the clinic.

\subsection{Disclosure of Status to Partner}

In this study $83.1 \%$ of participants had disclosed their HIV status to their partners. The disclosure rate in this study is higher compared to several studies on serostatus disclosure by pregnant women: 17.6\% [13], 31\% [14], 32\% [12], 65\% [11], 41\% [16], and 22\% [17]. Other studies, however, had higher disclosure rates: 79\% [18] and 83\% [19].

In this study, reasons given for non-disclosure includes HIV negative status (60.00\%), partners not asking (29.08\%), fear of divorce (3.64\%) and fear of violence from partners (3.64\%). Several studies have reported similar reasons for non-disclosure of HIV status to partners $[14,12,11,17,20]$. Our series shows that $60.00 \%$ of participants did not disclose their status because they were seronegative and so did not deem it important to disclose. This is in contrast with studies done in Tanzania where 85\% of HIV negative women disclosed their status to their partners [19]. HIV negative women in this study assume that because they are not infected, their partners are also not infected thus their reason for non-disclosure. This demonstrates a lack of understanding of serodiscordancy and is rather disturbing as these patients stand the risk of acquisition of HIV infection from infected partners if they are in a serodiscordant 
World Journal of Advanced Research and Reviews, 2020, 08(03), 014-027

relationship. Acute seroconversion in pregnancy is associated with a high risk of HIV transmission to the unborn baby due to high viraemia therefore putting the unborn baby at a very high risk of contracting HIV infection.

\subsection{Impact of HIV Disclosure}

All HIV status disclosures were done voluntarily. None of the participants experienced a negative impact of HIV status disclosure. Negative outcomes reported include 4\% domestic dispute without violence following HIV disclosure [14], and separation, physical assault, blame, anger disbelief and fear [13]. Positive outcomes of serostatus disclosure have also been reported: encouraging attitudes, partners' become understanding, acceptance and kindness [20] whilst some studies have reported indifference of some partners to serostatus disclosure [14, 20, 21].

Partner's support after serostatus disclosure have the following advantages: they offer the best environment for seropositive pregnant women to undergo a successful PMTCT program, the women are more likely to accept antiretroviral treatment or prophylaxis $[11,22,23]$ given at birth in a health facility and adhere to recommended HIV related care [24].

\subsection{Knowledge of Partner's HIV Status}

The majority of the study participants (70.76\%) did not know their partners' HIV status. This compares with a Tanzanian study by which showed that only $23 \%$ of study participants knew their partners' HIV status [16]. This lack of knowledge of partners' status has implications for HIV acquisition and transmission among partners who may happen to be in serodiscordant relationships. The reasons given for not knowing partners' HIV status includes; the participants not asking their partners $(81.9 \%)$ or partners not testing (18.1\%). Despite high disclosure rates among the pregnant women, their knowledge of their partners' HIV status was very low. This may be due to the fact that majority of the participants were HIV negative and they disclosed their status without enquiring of their partners' status. This could be happening due to lack of knowledge and understanding of serodiscordancy which means that the HIV education done at the Antenatal clinic has to properly address this issue.

\subsection{Serodiscordancy}

The level of serodiscordancy in the study participants could not be well established as most of the participants were not aware of their partners' HIV status. Consistent condom use is one of the key methods of prevention of HIV transmission. Participants in an assumed seroconcordant relationship who fail to use condoms may acquire HIV infection if the partner turns out to be seropositive. In a serodiscordant relationship, condom use is a key HIV preventive strategy. The study showed that participants' use of condoms was low with $1.48 \%$ almost always using condom, $15.48 \%$ using condoms occasionally and 83.04\% never using condoms. These findings support the finding that the prevalence of consistent condom use remains low in Ghana and in sub-Saharan Africa: $1.8 \%$ to $40 \%$ [25, 26, 27, 28].

Early testing of new born babies is important to the success of PMTCT programs. This allows for early detection of HIV infection allowing for early initiation of ART and improved survival of the infant. In this study only $27.05 \%$ of the participants with children had ever tested them for HIV infection. All the children tested were HIV seronegative. The low percentage of children tested could be explained by the high number of seronegative mothers whose children are not tested because they are not HIV exposed.

The study did not show a statistically significance relationship between disclosure of participants' HIV status and knowledge of HIV status (p-value: 0.51), however having had HIV education, participants' testing for HIV in current pregnancy, knowing partner's HIV status and having had children tested for HIV had a statistically significant relationship with disclosure of their HIV status (p-values $0.3,0.4,0.00$ and 0.21 respectively).

\section{Conclusion}

The study showed a relatively high level of disclosure of HIV test results by pregnant women to their sexual partners without them using the opportunity to enquire of partners' HIV status thus resulting in low level of knowledge of partners' HIV serostatus. Participants had very little knowledge of serodiscordancy. This has implications for the implementation of the use of PrEP as a preventive strategy in Ghana.

Male involvement in PMTCT has been primarily focussed on the HIV-infected women however it is also important to test partners of HIV-uninfected pregnant women in order to achieve the virtual elimination of MTCT of HIV. Male involvement has the potential to prevent seroconversion in the negative partner and improve uptake of HIV-prevention 
interventions among HIV-discordant couples, including treatment as prevention, PrEP, which would prevent horizontal acquisition or vertical transmission of HIV infection.

\title{
Limitations
}

The study was based on interview information, with disclosure being assessed based on self-reporting by clients. Over estimation or underestimation of the prevalence of disclosure cannot be ruled out as information obtained could not be verified. The findings could also have been biased as clients might have reported what they felt was expected.

\author{
Abbreviations \\ AIDS - Acquired immune deficiency syndrome \\ ANC - Antenatal clinic \\ ART - Antiretroviral therapy \\ ARVs -Antiretrovirals \\ FTC - Emtricitabine \\ GPRTU - Ghana private road transport union \\ HLA - Human leucocyte antigen \\ HIV - Human immunodeficiency virus \\ IDU - Injection drug use \\ MTCT - Mother-to-child transmission \\ NVP - Nevirapine \\ PCR - Polymerase chain reaction \\ PMTCT - Prevention of mother-to-child transmission \\ PrEP - Pre-exposure prophylaxis \\ PROTOA - Progressive transport owners' association \\ TDF - Tenofovir \\ UNAIDS - United Nations programme on HIV and AIDS \\ UNESCO - United Nations educational, scientific and cultural organization \\ VCT-Voluntary counselling and testing \\ WHO - World health organization \\ ZDV - Zidovudine
}

\section{Compliance with ethical standards}

\section{Acknowledgments}

Our heartfelt appreciation and thanks goes to the administration of Kumasi South Hospital, the clinical staff and clients at the hospital's antenatal clinic for their cooperation and willingness to be part of the research.

\section{Disclosure of conflict of interest}

All authors declare no competing interest

\section{Statement of ethical approval}

Ethical approval for the study was obtained from the institutional ethics committee.

\section{Statement of informed consent}

Informed consent was obtained from all participants included in the study.

\section{References}

[1] GBD 2013 Mortality and causes of Death Collaborators. Global, regional and national age-sex specific all cause and cause specific mortality for 240 causes of death, 1990-2013: a systemic analysis for the Global Burden of Disease Study 2013. Lancet. 2015; 385: 117.

[2] Centers for Disease Control and Prevention (CDC). The Global HIV/AIDS pandemic, 2006. MMWR Morb Mortal Wkly Rep. 2006; 55: 841. 
[3] Centers for Disease Control and Prevention. Revised guidelines for HIV counselling, testing and referral. MMWr Recomm Rep. 9Nov 2001; 50(RR-19): 1-57.

[4] Anand, Abhijeet, Ray W Shiraishi, Rebecca E Bunnell, Krista Jacobs, Nadia Solehdin, Abu S Abdul-Quader, Lawrence H Marum, et al. "Knowledge of HIV Status, Sexual Risk Behaviors and Contraceptive Need among People Living with HIV in Kenya and Malawi:" AIDS 23, no. 12. July 2009; 1565-73.

[5] Dunkle, Kristin L, Rob Stephenson, Etienne Karita, Elwyn Chomba, Kayitesi Kayitenkore, Cheswa Vwalika, Lauren Greenberg, and Susan Allen. "New Heterosexually Transmitted HIV Infections in Married or Cohabiting Couples in Urban Zambia and Rwanda: An Analysis of Survey and Clinical Data." The Lancet 371, no. 9631. June 2008; 2183-91.

[6] Madiba, Sphiwe. "HIV Disclosure to Partners and Family among Women Enrolled in Prevention of Mother to Child Transmission of HIV Program: Implications for Infant Feeding in Poor Resourced Communities in South Africa." Global Journal of Health Science 5, no. 4. 7 March 2013; 1.

[7] Wong, Lauren H, Heidi Van Rooyen, Precious Modiba, Linda Richter, Glenda Gray, James A McIntyre, Christine Dunkel Schetter, and Thomas Coates. "Test and Tell: Correlates and Consequences of Testing and Disclosure of HIV Status in South Africa (HPTN 043 Project Accept):" JAIDS Journal of Acquired Immune Deficiency Syndromes 50, no. 2. February 2009; 215-22.

[8] Kassaye, Kebede Deribe, Wassie Lingerh, and Yismaw Dejene. "Determinants and Outcomes of Disclosing HIVSero Positive Status to Sexual Partners among Women in Mettu and Gore Towns, Illubabor Zone Southwest Ethiopia." Ethiopian Journal of Health Development 19, no. 2.27 October 2005; 126-31.

[9] Desgrees-du-Lou A, Brou H, Traore AT, Djohan G, Becquet R, Leroy V. From prenatal HIV testing of the mother to prevention of sexual HIV transmission within the couple. Soc Sci Med. 2009; 69(6): 892-9.

[10] Shamu, Simukai, Christina Zarowsky, Tamara Shefer, Marleen Temmerman, Naeemah Abrahams. "Intimate Partner Violence after Disclosure of HIV Test Results among Pregnant Women in Harare, Zimbabwe." Edited by Michael Hoonbae Chung. PLoS ONE 9, no. 10. 28 October 2014; e109447.

[11] Farquhar, Carey, Dorothy A. Mbori-Ngacha, Rose K. Bosire, Ruth W. Nduati, Joan K. Kreiss, Grace C. John. "Partner Notification by HIV-1 Seropositive Pregnant Women: Association with Infant Feeding Decisions:” AIDS 15, no. 6. April 2001; 815-17.

[12] Gaillard, Philippe, Reinhilde Melis, Fabian Mwanyumba, Patricia Claeys, Esther Muigai, Kishorchandra Mandaliya, Job Bwayo, Marleen Temmerman. "Vulnerability of Women in an African Setting: Lessons for Mother-to-Child HIV Transmission Prevention Programmes:” AIDS 16, no. 6. April 2002; 937-39.

[13] Nebié, Yacouba, Nicolas Meda, Valériane Leroy, Laurent Mandelbrot, Seydou Yaro, Issiaka Sombié, Michel Cartoux, et al. "Sexual and Reproductive Life of Women Informed of Their HIV Seropositivity: A Prospective Cohort Study in Burkina Faso:" JAIDS Journal of Acquired Immune Deficiency Syndromes 28, no. 4. December 2001; 367-72.

[14] Issiaka S, M. Cartoux O. Ky-Zerbo, S. Tiendrebéogo, N. Meda, F. Dabis, P. Van de Perre. “Living with HIV: Women's Experience in Burkina Faso, West Africa.” AIDS Care 13, no. 1. February 2001; 123-28.

[15] Rujumba, Joseph, Stella Neema, Robert Byamugisha, Thorkild Tylleskär, James K Tumwine, Harald K Heggenhougen. “'Telling My Husband I Have HIV Is Too Heavy to Come out of My Mouth': Pregnant Women's Disclosure Experiences and Support Needs Following Antenatal HIV Testing in Eastern Uganda." Journal of the International AIDS Society 15, no. 2. 14 August 2012.

[16] Kiula, Elizabeth S, Damian J Damian, Sia E Msuya. "Predictors of HIV Serostatus Disclosure to Partners among HIV-Positive Pregnant Women in Morogoro, Tanzania.” BMC Public Health 13, no. 1. December $2013 ; 433$.

[17] Antelman, Gretchen, Mary C. Smith Fawzi, Sylvia Kaaya, Jessie Mbwambo, Gernard I. Msamanga, David J. Hunter, Wafaie W. Fawzi. "Predictors of HIV-1 Serostatus Disclosure: A Prospective Study among HIV-Infected Pregnant Women in Dar Es Salaam, Tanzania:" AIDS 15, no. 14. September 2001; 1865-74.

[18] Straten, Ariane van der, Rachel King, Olga Grinstead, Antoine Serufilira, and Susan Allen. "Couple Communication, Sexual Coercion, and HIV Risk Reduction in Kigali, Rwanda:” AIDS 9, no. 8. August 1995; 935-44.

[19] Maman, Suzanne, Jessie K. Mbwambo, Nora M. Hogan, Ellen Weiss, Gad P. Kilonzo, Michael D. Sweat. "High Rates and Positive Outcomes of HIV-Serostatus Disclosure to Sexual Partners: Reasons for Cautious Optimism from a Voluntary Counseling and Testing Clinic in Dar Es Salaam, Tanzania." AIDS and Behavior 7, no. 4. December 2003; 373-82. 
[20] Keogh, P, S. Allen, C. Almedal, B. Temahagili. "The Social Impact of HIV Infection on Women in Kigali, Rwanda: A Prospective Study." Social Science \& Medicine 38, no. 8. April 1994; 1047-53.

[21] Bennets A, Shaffer N, Manopaiboon C, Chaiyakul P, Siriwan W, Mock P et al. Determinants of depression and HIV related worry among HIV positive women who have recently given birth, Bangkok, Thailand. Social Science and Medicine. 1999; 49: 737-49.

[22] Roxby, Alison C, Daniel Matemo, Alison L. Drake, John Kinuthia, Grace C. John-Stewart, Francisca Ongecha-Owuor, James Kiarie, and Carey Farquhar. "Pregnant Women and Disclosure to Sexual Partners After Testing HIV-1Seropositive During Antenatal Care." AIDS Patient Care and STDs 27, no. 1. January 2013; 33-37.

[23] Kiarie, James N, Joan K Kreiss, Barbra A Richardson, and Grace C John-Stewart. "Compliance with Antiretroviral Regimens to Prevent Perinatal HIV-1 Transmission in Kenya:" AIDS 17, no. 1. January 2003; 65-71.

[24] Kalembo, Fatch W, Maggie Zgambo, Atupele N. Mulaga, Du Yukai, and Niman I. Ahmed. "Association between Male Partner Involvement and the Uptake of Prevention of Mother-to-Child Transmission of HIV (PMTCT) Interventions in Mwanza District, Malawi: A Retrospective Cohort Study." Edited by Patricia Kissinger. PLoS ONE 8, no. 6. 12 June 2013; e66517.

[25] Anyangu, As. "Prevalence and Factors Influencing Consistent Condom Use among Sexually Active Young People Attending a Youth Friendly Centre in Kenya, 2008." East African Journal of Public Health 7, no. 4. 25 March 2011.

[26] Karim AM, Magnani RJ, Morgan GT, Bond KC. Reproductive health risk and protective factors among unmarried youth in Ghana. Int Fam Plan Perspect. Mar 2003; 29(1): 14-24.

[27] Grosso, Ashley L., Esther L. Lei, Sosthenes C. Ketende, Sarah Peitzmeier, Krystal Mason, Nuha Ceesay, Daouda Diouf, et al. "Correlates of Condom Use among Female Sex Workers in The Gambia: Results of a Cross-Sectional Survey." PeerJ 3. 6 August 2015; e1076.

[28] Abdul-Kabir M, Otupiri E, Opare D. Barrier to Condom use among the Youth in a Municipal Town in Ghana. Journal of the Ghana Science Association. 2007; 9(2): 76-84. 